\title{
Value-Driven Health Care: Implications for Hospitals and Hospitalists
}

\author{
Patrick H. Conway, mD, msc ${ }^{1,2,3} \quad{ }^{1}$ U.S. Department of Health and Human Services, Washington, DC. \\ ${ }^{2}$ Center for Health Care Quality and Division of Health Policy and Clinical Effectiveness, \\ Cincinnati Children's Hospital Medical Center, Cincinnati, Ohio. \\ ${ }^{3}$ Division of General Pediatrics, Cincinnati Children's Hospital Medical Center, Cincinnati, Ohio.
}

Disclaimer: The views expressed in this manuscript represent the author and do not represent official policy or opinions of the Department of Health and Human Services.

There is increasing concern about the quality and cost of health care delivered in the United States. This has led to a focus on value-driven health care, meaning how we can achieve better quality outcomes per dollar spent on health care. Since a large percentage of costs and patient outcomes are directly related to care received in the hospital, the focus on value-driven health care by policymakers and payers is likely to increasingly impact hospitals and hospitalists. Hospitalists can play an essential role in leading and facilitating programs to improve hospital system performance. There are many government initiatives and policies focused on improving quality and value with major implications for hospitals and hospitalists, including: value-based purchasing, quality and cost reporting, Medicare demonstrations, hospital-acquired conditions, incentives for use of effective health information technology (HIT), and the Physician Quality Reporting Initiative (PQRI). The goal of these programs is to reward hospitals and physicians who achieve high-quality, efficient care. As our system and its incentives continue to progress toward alignment with value-based high-quality care, hospitalists should lead change and facilitate solutions to transform our health care system to one that provides high-value care to all. Journal of Hospital

Medicine 2009;4:507-511. (C) 2009 Society of Hospital Medicine.

KEYWORDS: health policy, hospitalists, pay-for-performance, value-driven health care.

It is estimated that the Medicare Part A trust fund will be exhausted by 2016 to 2019; also, the quality of care delivered in the United States is highly variable. ${ }^{1-3}$ Value is typically defined as the quality achieved for a given cost (ie, value $=$ quality/cost). The focus on the 3 related concepts of value, quality, and cost of health care is likely to continue to increase. Previously, the U.S. Department of Health and Human Services (HHS) made value-driven health care one of the Department's top priorities. ${ }^{4}$ Policymakers are in a period of transition but the publicly available plans of the President and Senate leadership indicate that the focus on value-based initiatives will likely continue to increase as our nation strives to achieve better outcomes for our health care dollar. $^{5,6}$ Specifically, the federal government and other payers increasingly align payment incentives with value and quality, encourage public reporting on quality and Medicare payment costs, such as on the Hospital Compare website (http://www.hospitalcompare.hhs.gov), and implement and evaluate demonstrations to test mechanisms such as health information technology (HIT) to improve value-based performance.

Since hospital care represented $\$ 648$ billion in 2006, which is $37 \%$ of the total patient-related U.S. health care expenditure, the trend to pay for value will likely have significant impact on hospitals and hospitalists. ${ }^{7}$ The Society of Hospital Medicine has a public policy committee that provides feedback to government on programs and policies related to value-driven health care. The policies and pro- grams need consideration and input from the broader community of hospitalists. This work outlines some of the major national initiatives and policies focused on value-driven health care and their implications for hospitalists. Hospitalists will need to understand the policy landscape and trends, lead improvement in their individual hospitals to receive value-based incentives, and assess the opportunities and challenges of current and potential payer programs and policies.

\section{Policies and Initiatives: Implications for Hospitals and Hospitalists}

Within the portfolio of value-driven health care, there are at least 6 major government programs, initiatives, and policies with implications for hospitals and hospitalists: value-based purchasing (VBP), quality and cost public reporting, Medicare demonstrations, hospital-acquired conditions, incentives for use of effective HIT, and the physician quality reporting initiative (PQRI) (Table 1).

\section{Value-Based Purchasing}

The Deficit Reduction Act Section 5001(b) authorized the Centers for Medicare and Medicaid Services (CMS) to develop a Medicare hospital VBP plan. The VBP plan is currently in the Presidents FY10 budget and the senate Committee's specification for health reform. VBP involves at least a portion of the payment being related to value instead of the traditional fee-for-service (FFS) model. CMS has 


\section{TABLE 1. Summary of Select Value-Driven Initiatives and Policies}

\begin{tabular}{ll} 
Initiative or Policy & Description \\
\hline Value-based purchasing & $\begin{array}{c}\text { At least a portion of hospital payment } \\
\text { related to value instead of the traditional } \\
\text { fee-for-service model } \\
\text { Payment based on hospital Total } \\
\text { Performance Score }\end{array}$
\end{tabular}

Public reporting of quality and cost

Medicare demonstrations

Hospital-acquired conditions

Incentives for use of effective health information technology

Physician Quality Reporting Initiative (PQRI)

CMS has demonstration projects to test concepts, such as value-based purchasing, incentive payments, and care management, aimed at improving the value of care delivered

CMS rule that the presence of a select group of reasonably preventable conditions as the only complicating condition will not cause a higher-paying diagnosis-related group (DRG) to be

Incentives for HIT use, often focused on certified interoperable systems and/or quality reporting, are provided by federal and private payers

Quality measures linked to $2 \%$ incentive payment to physicians and other

\section{Specific Examples}

Performance score is based on domains such as process measures (eg, betablocker at discharge for acute myocardial), outcome measures (eg, 30day AMI mortality), and satisfaction measures (eg, Consumer Assessment of Healthcare Providers and Hospital Survey, aka HCAHPS)

HospitalCompare reports process measures (eg, percent of heart failure patients given discharge instructions), outcome measures (eg, 30-day risk-adjusted mortality for AMI), survey of patients' hospital experience, and Medicare payment and volume for certain conditions assigned to the case practitioners for reporting quality measures via claims or registry
Premier Hospital Quality Incentive Demonstration: Differentiates payment to hospitals based on performance on 30 metrics

Acute Care Episode (ACE) Demonstration: Provides bundled payments for select orthopedic and cardiovascular inpatient procedures

Medicare Hospital Gainsharing Demonstration: Hospitals can provide gainsharing payments to physicians based on savings from improving quality and efficiency

First 10 implemented:

Foreign object retained after surgery; Air embolism;

Blood incompatibility;

Stage III and IV pressure ulcers;

Falls and trauma;

Manifestations of poor glycemic control;

Catheter-associated urinary tract

infections;

Vascular catheter-associated infection;

Surgical site infection following specific surgeries;

Deep vein thrombosis and pulmonary embolus

The American Recovery and Reinvestment Act included over \$17 billion of HIT incentives

Incentive money was directed at hospitals (hospital-based physicians were excluded) and ambulatory physicians are eligible for direct incentives

Examples of measures hospitalists can report on include:

Deep vein thrombosis prophylaxis for ischemic stroke or intracranial hemorrhage;

Medication reconciliation at discharge: Advance care plan documented; Oral antiplatelet therapy for patients discharged with stroke diagnosis

\section{Potential Implications}

Hospitalists will influence hospital performance on Total Performance Score and could lead quality improvement efforts to improve score

Many of these measures are directly related to care provided by hospitalists

Hospitalists could lead quality improvement initiatives focused on these measures

Hospitals with their associated hospitalists can apply to participate in these and other demonstrations

Successful demonstrations can be expanded or components incorporated into payment policy

Hospitalists can lead or participate in safety initiatives to decrease or eliminate these complications

Front line providers, including hospitalists, need to help guide implementation of HIT to be successful

Systems that include physician order entry, clinical decision support, and quality measurement capture and reporting can help hospitalists deliver higher quality care

Hospitalists can drive performance on these measures, lead reporting efforts, and share in the financial rewards 
consulted with external stakeholders on the measures, data infrastructure and validation, and incentive structure for the proposed program. Hospitals would submit data for all VBP measures that apply and performance scores would be given based on both attainment and improvement. The higher of the 2 scores (ie, attainment or improvement) would represent the hospital's performance in a given domain and the weighted domain scores would determine the hospital's total performance score. This total performance score would then be translated into an incentive payment for the hospital. Measure domains would include process measures (eg, beta-blocker at discharge for acute myocardial infarction [AMI]), outcome measures (eg, 30-day AMI mortality), and satisfaction measures (eg, Consumer Assessment of Healthcare Providers and Systems Hospital survey [HCAHPS]). Hospitalists are in a unique position to impact and improve performance in all of the above domains for hospitals. This has the potential to increase the value of high-performing hospitalist groups to their respective hospitals. Most importantly, this program aligns incentives with rewarding the provision of high-quality care as defined by these measures. Over time, CMS may consider expanding the measures to other domains such as efficiency, more patient-centered outcomes, and care coordination. In terms of efficiency measurement, the Medicare Improvements for Patients and Providers Act (MIPPA) passed in 2008 called for CMS to provide confidential reports to physicians or groups of physicians on their relative resource use. This legislation also called for HHS to develop a plan for transitioning to VBP for Medicare professional services and a report to Congress on this plan. ${ }^{9}$ This lays the foundation for transforming Medicare to focus more on quality, resource use, and value and less on FFS.

\section{Public Reporting of Quality and Cost}

CMS is beginning to empower consumers with information on quality and Medicare payment costs so they can make educated decisions on where and how they seek care. The CMS website focused on hospitals is HospitalCompare (http://www.hospitalcompare.hhs.gov). This website reports process measures for myocardial infarction, heart failure, pneumonia, surgical care improvement, and asthma care for children; outcome measures for risk-adjusted mortality from myocardial infarction, heart failure, and pneumonia; patient experience of care from HCAHPS; and the patient volume and average Medicare payment for specific diagnosis-related groups (DRGs). ${ }^{10}$ It is a step toward empowering consumers with information, and will likely continue to expand. Reporting this information also has the potential to increase competition between providers to perform better than their peers and achieve higher-quality care. Hospitalists, as quality improvement leaders and bedside clinicians, are critical to improving the performance of hospitals on most of these measures.

\section{Medicare Demonstrations}

Several Medicare demonstration projects already implemented or in the planning stages are particularly relevant to hospitals and hospitalist practice. These demonstrations test concepts, such as VBP, incentive payments, and care management, aimed at improving the value of care delivered. If demonstrations are successful, they have potential for incorporation into federal policy. The "Premier Hospital Quality Incentive Demonstration" is an incentive program that differentiates payment to hospitals based on performance on 30 quality measures. Participation is voluntary. The top $20 \%$ of hospitals receive incentive payments. ${ }^{11}$ The success of this demonstration led to its current second phase. The "Acute Care Episode (ACE) Demonstration" will provide bundled payments (including Part A and B services) for ACEs within Medicare FFS. The demonstration includes gainsharing by allowing sites to reward individual clinicians, teams of clinicians, or other hospital staff who show measurable clinical quality improvement. The focus is on select orthopedic and cardiovascular inpatient procedures (eg, hip/knee replacement surgery and coronary artery bypass graft surgery). ${ }^{12}$ The demonstration also has potential to increase volume to participant physician-hospital organizations through financial incentives to beneficiaries via payments to offset their Medicare cost-sharing obligations. If this demonstration is successful and the concept of bundled payment is expanded to other conditions and additional geographies, this could have significant impact on hospitalists. Specifically, programs for care coordination and reducing readmissions and complications after discharge would be directly incentivized. The demonstration focuses on Texas, Oklahoma, Colorado, and New Mexico. The "Medicare Hospital Gainsharing Demonstration" program to test and evaluate arrangements between hospitals and physicians is designed improve the quality and efficiency of care provided to beneficiaries. The demonstration allows hospitals to provide gainsharing payments to physicians that represent solely a share of the savings incurred as a result of collaborative efforts to improve overall quality and efficiency. The demonstration was launched in 2007. ${ }^{13}$ Finally, the upcoming "Medicare Medical Home Demonstration" has the potential for direct or indirect hospitalist participation as facilitators in Tier 2 medical homes that take into account care coordination across inpatient and outpatient settings. ${ }^{14}$ These demonstrations represent attempts by the federal government to align incentives with high-quality, high-value delivery of care.

\section{Hospital-Acquired Conditions}

Hospital-acquired conditions (HACs) have significant cost and quality implications for U.S. healthcare, such as the estimated 99,000 deaths associated with hospital-acquired infections annually. ${ }^{15}$ Therefore, CMS received statutory authority to not pay additional charges for "reasonably preventable" HACs. Beginning October 1, 2008, CMS implemented a rule 
that the presence of selected reasonably preventable conditions as the only complicating condition would not cause a higher-paying DRG to be assigned to the case; therefore, the case would be paid as though the secondary diagnosis were not present. CMS also required the reporting of a new data element to delineate HACs from conditions present on admission. Hospitals can indicate to CMS if a condition was present on admission as a secondary diagnosis, allowing reimbursement for care provided to treat any condition present on admission. The first 10 HACs to be implemented were: foreign object retained after surgery, air embolism, blood incompatibility, stage III and IV pressure ulcers, falls and trauma, manifestations of poor glycemic control, catheterassociated urinary tract infections, vascular catheter-associated infection, surgical site infection following specific surgeries, and deep vein thrombosis and pulmonary embolus. ${ }^{16}$ Since some complications are not absolutely preventable and evidence-based guidelines for the prevention of some complications are lacking, this has generated some resistance from the provider community. ${ }^{17}$ The HAC payment policy is a step toward aligning incentives with quality performance, but any further HACs will need to be evaluated for their level of preventability and potential for unintended consequences.

\section{Incentives for Use of Effective HIT}

The use of HIT can be incentivized in 3 main ways, all of which are likely to increase over time. First, incentives can be implemented to reward reporting quality metrics via electronic health records or registries. Second, incentives based on quality performance may indirectly encourage the adoption of HIT because an electronic medical record, especially with computerized provider order entry and decision support, may enable higher performance on quality metrics. Finally, CMS has provided direct incentives for information technology adoption, such as certified electronic health records. ${ }^{18}$ The American Recovery and Reinvestment Act of 2009 created over $\$ 17$ billion of potential incentive payments for HIT use by physicians and hospitals. ${ }^{19}$ Hospitals are eligible for significant incentives reaching estimates over $\$ 6$ million per year, phasing out by 2015, so Congress excluded hospital-based physicians from direct payments. Ambulatory physicians are eligible for up to $\$ 18,000$ per year, phasing out by 2015, with subsequent payment reductions for nonuse. Since hospitalists often function at the nexus of clinical care, quality improvement, and technology use, they have the opportunity to lead or facilitate effective implementation of information technology in their hospitals. These efforts may be rewarded by hospitals.

\section{PQRI}

PQRI was authorized in 2006 and included a 1.5\% incentive payment for satisfactorily reporting quality data. The incentive payment will increase to $2 \%$ in 2009 . There are 153 PQRI measures in 2009 and a significant number of the measures focus on hospital-based care. Examples of meas- ures hospitalists can help report include: deep vein thrombosis prophylaxis for ischemic stroke or intracranial hemorrhage, medication reconciliation at discharge, advance care plan documentation, oral antiplatelet therapy for patients discharged with stroke diagnosis, and anticoagulant therapy prescribed for atrial fibrillation in stroke patients at discharge. PQRI measures can be reported through claimsbased or registry-based reporting. Reporting can be done on individual measures or for measure groups associated with specific conditions. ${ }^{20}$ Hospitalists have the potential to drive performance on these measures, lead reporting efforts, and share in the financial rewards.

\section{Future Considerations}

The political leadership at the federal and state level is beginning a new transition; however, the focus on quality and value for our health care dollar will likely continue to increase. ${ }^{5,6}$ The U.S. health care system has untenable cost estimates, significant quality gaps, and a fractured payment system that fails to reward effective care coordination. ${ }^{2,21,22}$ This increased focus on quality and value should be viewed as an opportunity for hospitalists and hospitals. Hospitalist groups that can achieve high-quality performance will be increasingly valued, and hospitals should further recognize the critical role hospitalists play in achieving high performance and the associated financial rewards. Hospitalists often lead quality improvement and safety programs in hospitals, and these programs are likely to be seen as progressively more important as payment is linked to performance. The Society of Hospital Medicine engages with policymakers and this role is increasingly significant as more policy and payment decisions impact hospitalists. The Society has focused on collaborative work with payers, policymakers, and other providers to find joint shared solutions. Hospitalists can serve as a link between providers and a focal point of care coordination, especially for the hospitalized patient. Finally, as our system and its incentives continue to progress toward alignment with value-based high quality care, hospitalists should be leading the change and be an essential part of the solution to transform our health care system to provide high-quality, efficient care to all Americans.

\section{Acknowledgements}

Dr. Tom Valuck is recognized for his thoughtful comments and edits in preparation, submission, and revision of this manuscript.

\section{Address for correspondence and reprint requests:}

Patrick H. Conway, MD, MSc, 200 Independence Avenue, Room 447D.3, Washington, DC 20201; Telephone: 202-690-7388; Fax: 202-690-7383; E-mail: patrick.conway@hhs.gov Received 23 November 2008; revision received 9 March 2009; accepted 12 April 2009.

\section{References}

1. Medicare Board of Trustees. A Summary of the 2008 Report. Available at: http://www.ssa.gov/OACT/TRSUM/trsummary.html. Accessed April 2009.

2. McGlynn EA, Asch SM, Adams J, et al. The quality of health care delivered to adults in the United States. N Engl J Med. 2003;348(26):2635-2645. 
3. Economy Likely to Move up Medicare's Insolvency. Available at: http:// abcnews.go.com/Politics/Health/wireStory?id=6369658. Accessed April 2009.

4. Value-Driven Health Care. Available at: http://www.hhs.gov/valuedriven. Accessed April 2009.

5. Obama-Biden Full Health Care Plan. Available at: http://www.barackobama. com/issues/healthcare. Accessed April 2009.

6. Senate Chairman Max Baucus Call to Action Health Reform 2009. Available at: http://finance.senate.gov/healthreform2009/finalwhitepaper.pdf. Accessed April 2009.

7. Catlin A, Cowan C, Hartman M, Heffler S. National health spending in 2006: a year of change for prescription drugs. Health Aff (Millwood). 2008;27(1):14-29.

8. Medicare Hospital Value-Based Purchasing Plan. October 31, 2008. Available at: http://www.cms.hhs.gov/AcuteInpatientPPS/downloads/hospital_ VBP_plan_issues_paper.pdf. Accessed April 2009.

9. Medicare Improvements for Patients and Providers Act of 2008. Available at: http://www.asm.org/ASM/files/ccLibraryFiles/Filename/000000004120/ HR6331.pdf. Accessed April 2009.

10. HospitalCompare. Available at: www.hospitalcompare.hhs.gov. Accessed April 2009.

11. Premier Hospital Quality Incentive Demonstration. Available at: http:// www.cms.hhs.gov/HospitalQualityInits/35_hospitalpremier.asp. Accessed April 2009.

12. Acute Care Episode Demonstration. Available at: http://www.cms.hhs.gov/ DemoProjectsEvalRpts/MD/itemdetail.asp?filterType $=$ none\&filterByDID $=$ 99\&sortByDID=3\&sortOrder $=$ descending\&itemID $=C M S 1204388 \&$ intNum PerPage $=10$. Accessed April 2009.
13. Details for DRA 5007 Medicare Hospital Gainsharing Demonstration. http://www.cms.hhs.gov/DemoProjectsEvalRpts/MD/itemdetail.asp?filterType $=$ none $\&$ filterByDID $=99 \&$ sortByDID $=3 \&$ sortOrder $=$ descending\&itemID $=$ CMS1186805\&intNumPerPage $=10$. Accessed April 2009.

14. Medicare Medical Home Demonstration. Available at: http://www.cms. hhs.gov/DemoProjectsEvalRpts/MD/itemdetail.asp?filterType=none\&filterByDID $=-99 \&$ sortByDID $=3 \&$ sortOrder $=$ descending\&itemID $=\mathrm{CMS1} 199247 \&$ intNumPerPage $=10$. Accessed April 2009.

15. Klevens RM, Edwards JR, Richards CL Jr, et al. Estimating health careassociated infections and deaths in U.S. hospitals, 2002. Public Health Rep. 2007;122(2):160-166.

16. Hospital Acquired Conditions. Available at: http://www.cms.hhs.gov/ HospitalAcqCond/06_Hospital-Acquired_Conditions.asp. Accessed April 2009 .

17. Pronovost PJ, Goeschel CA, Wachter RM. The wisdom and justice of not paying for "preventable complications". JAMA. 2008;299(18):2197-2199.

18. E-prescribing incentive program. Available at: http://www.cms.hhs.gov/ ERXincentive. Accessed April 2009.

19. American Recovery and Reinvestment Act. Available at: http://frwebgate. access.gpo.gov/cgi-bin/getdoc.cgi?dbname=111_cong_bills\&docid=f:hlenr. pdf. Accessed April 2009.

20. Physician Quality Reporting Initiative Overview. Available at: http:// www.cms.hhs.gov/PQRI. Accessed April 2009.

21. Congressional Budget Office. The long-term outlook for health spending. Available at: http://www.cbo.gov/doc.cfm?index $=8758$. Accessed April 2009.

22. Dougherty D, Conway PH. The "3T's" road map to transform US health care: the "how" of high-quality care. JAMA. 2008;299(19):2319-2321. 